\title{
Controlling medicine prices in Sudan: the challenge of the recently established Medicines Regulatory Authority
}

G.K.M. Ali and A.Y. Yahia ${ }^{2}$

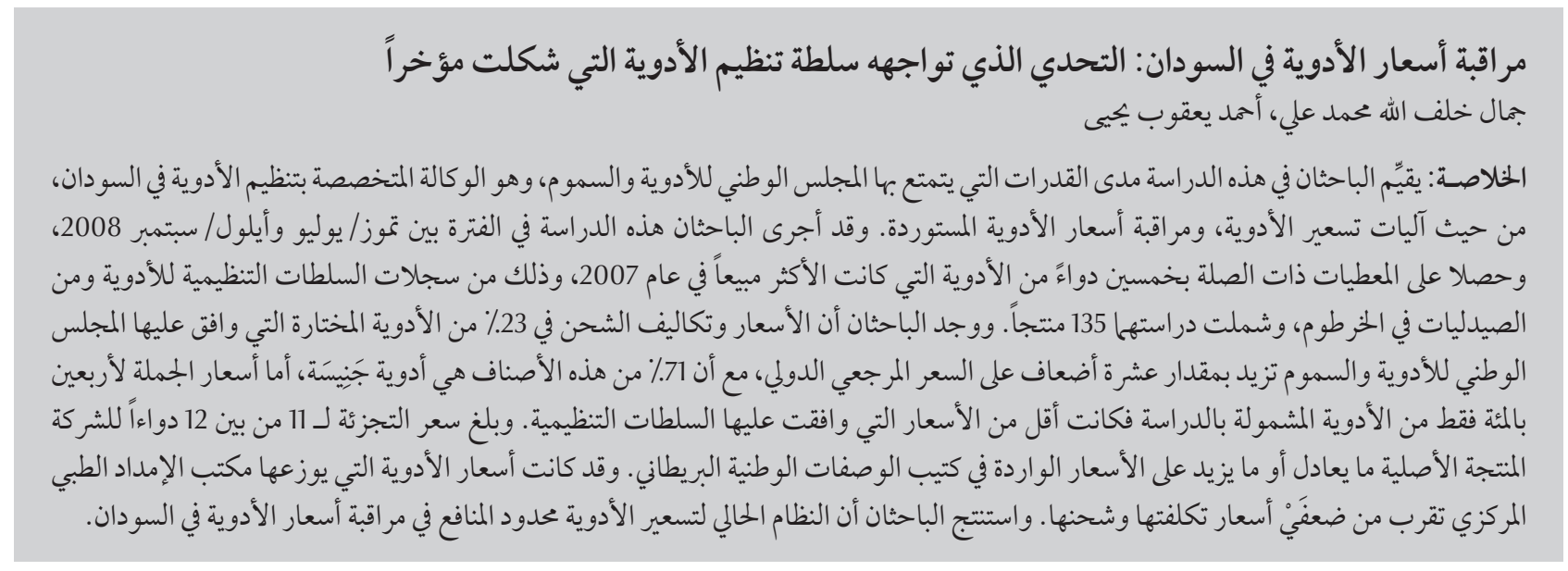

ABSTRACT This study evaluated the capacity of the medicine pricing mechanism of the National Medicines and Poisons Board (NMPB), the medicine regulatory agency of Sudan, in controlling prices of imported medicines. The study was conducted between July and September 2008 and data on the 50 most sold medicines in 2007 were obtained from the records of the regulatory authority and pharmacies in Khartoum; 135 products were included. The cost and freight (C\&F) prices of 23\% of the selected medicines approved by NMPB were over 10 times the International Reference Price; $71 \%$ of these items were generics. The wholesale price of only $40 \%$ of the studied medicines was less than that approved by NMPB, while the retail price of $47 \%$ of medicines was less than that approved by the authority. The retail price of 11 of 12 originator medicines was equal to or more than their prices published in the British National Formulary. The price of the medicines distributed by Central Medical Supplies was about 2-fold their C\&F price. The current pricing system is of limited benefit in controlling medicine prices in Sudan.

Contrôle des prix des médicaments au Soudan : un défi pour l'autorité de réglementation pharmaceutique récemment établie

RÉSUMÉ La présente étude a évalué la capacité du mécanisme de tarification des médicaments du Comité national des médicaments et des poisons -l'agence de réglementation des produits pharmaceutiques au Soudanà contrôler les prix des médicaments importés. L'étude a été menée entre juillet et septembre 2008. Les données sur les 50 marques les plus vendues en 2007 ont été obtenues à partir des dossiers de l'autorité de réglementation et des pharmacies de l'État de Khartoum. Au total, 135 produits ont été inclus dans l'étude. Le chiffrage du coût et du fret de $23 \%$ des médicaments sélectionnés et autorisés par le Comité national des médicaments et des poisons était dix fois plus élevé que le prix de référence international ; $71 \%$ de ces produits étaient des génériques. Le prix de gros de $40 \%$ des médicaments étudiés seulement était inférieur au prix approuvé par le Comité national, alors que le prix de détail de $47 \%$ des médicaments était plus faible que celui approuvé par l'autorité de réglementation. Le prix de détail de 11 médicaments de marque (princeps) sur 12 était supérieur ou équivalent aux prix publiés dans le Formulaire national britannique. Le prix des médicaments distribués par Central Medical Supplies était environ le double des montants du coût et du fret des produits. Le système actuel de tarification est d'un intérêt limité pour le contrôle des prix des médicaments au Soudan. 


\section{Introduction}

In Sudan, a pricing mechanism has been built into the registration system as a routine administrative exercise from the very beginning of medicine registration. Affordability is a critical factor in a country like Sudan, where poverty is deep and widespread. Such a situation increases the vulnerability of wide segments of the population to ill health. According to the Sudan Central Bureau of Statistics, over 45\% of the population in Sudan is below the poverty line [1]. More than $70 \%$ pay out-of-pocket at both public and private sector facilities to meet their medical needs [2].

In 2001, the Sudanese government passed an act regulating the prices of medicines in Sudan in both the public and private sector [3]. According to a technical discussion on medicine prices and access to medicines in the Eastern Mediterranean Region held by the World Health Organization (WHO), Regional Office for the East Mediterranean in 2007, prices of medicines in Sudan were among the highest in the Region [4]. The act was updated in 2009 and renamed the Medicines and Poisons Act.

Published studies on how governments in developing countries regulate prices of medicines are relatively few [5]. Although it is possible to know how much gets added on to a manufacturer's prices in the supply chain, it is not clear how much exporting pharmaceutical companies actually spend on production and thus the real revenues needed to meet their costs and still make a profit. In addition, how governments regulate the cost and freight $(\mathrm{C} \& \mathrm{~F})$, whole and retail prices in both public and private sectors is still widely unknown. Typically the largest mark-ups in addition to taxes and duties are the importers', wholesalers' and retailers' margins, which can add $35 \%$ to $70 \%$ to the factory price [4].
The aim of this study was to evaluate the current medicine pricing system used by the National Medicines and Poisons Board (NMPB) (the medicine regulatory agency of Sudan). Our objectives were to:

- check the conformity of the wholesale and retail prices of medicines with those approved by the NMPB;

- assess the adherence of pharmacies to the formal retail prices set by the wholesalers/importers and published on their invoices;

- compare prices of generic medicines with those of the proprietary medicines and the prices of selected medicines with those cited in the International Price Indicator published by Management Sciences for Health widely known as IRP [6] and British National Formulary (BNF), which is accepted by NMPB as an independent reference for medicines prices [7]. MSH reference prices are the medians of recent procurement or tender prices offered by not-for-profit suppliers to developing countries for multi-source products;

- gather evidence on compliance with price regulation in Sudan and demonstrate violation of the official prices set by regulatory agency and importers;

- put forward recommendations to obtaining more accurate measures of overall price differences.

Assessment of the pricing mechanism for locally manufactured medicines was not undertaken in this study.

\section{Background}

Prior to marketing in Sudan, a medicine must be registered with NMPB with a C\&F price approved by NMPB. NMPB issues a certificate of registration, which displays, in addition to other information, the C\&F price. The certificate of registration is valid for 5 years after which the product must be reregistered. However, in accepting the
C\&F price, the current system does not guarantee its sustainability during the life-span of the certificate of registration. It allows changes to registered $\mathrm{C} \& \mathrm{~F}$ prices in response to changed economic circumstances, such as fluctuations in the exchange rate and adjustments for inflation over the life of the certificate. The current system requires local manufacturers and importers to get the approval of NMPB for price change (increase or decrease) with an explanation prior to applying new prices.

\section{Pricing system in the private sector}

Pharmaceutical prices are regulated by the Pharmacy and Poisons Act [3]. Based on a medicine's total C\&F (i.e. wholesalers add a fixed percentage to the price they pay for the manufacturers from abroad), NMPB fixes maximum percentage mark-ups for all medicines for 2 stages of the distribution. Wholesaler's profit is $15 \%$ of the total costs to their central warehouses in Khartoum, and retailer's profit is $20 \%$ of the wholesaler's price (Figure 1).

The system thus creates a leveraging effect whereby wholesalers and retailers respectively race to import and dispense expensive medicines that give them higher profit margins. These inflated prices compromise patient access to medicines. The price of medicines is one of several reasons for lack of access to essential medicines. It has been reported that less than 50\% of the Sudanese population has regular access to the essential medicines [8]. No government value added tax is applied along the supply-chain. The government tax $1.5 \%$ of purchasing prices in the case of retailers and charge a $15 \%$ profit tax to be paid by importers. Importers are required to stamp the final price to consumers on the medicine packages sold to pharmacies [9].

The standing medicine pricing committee within the NMPB, determines the $C \& F$ acquisition unit cost to the destination named by importers (in 


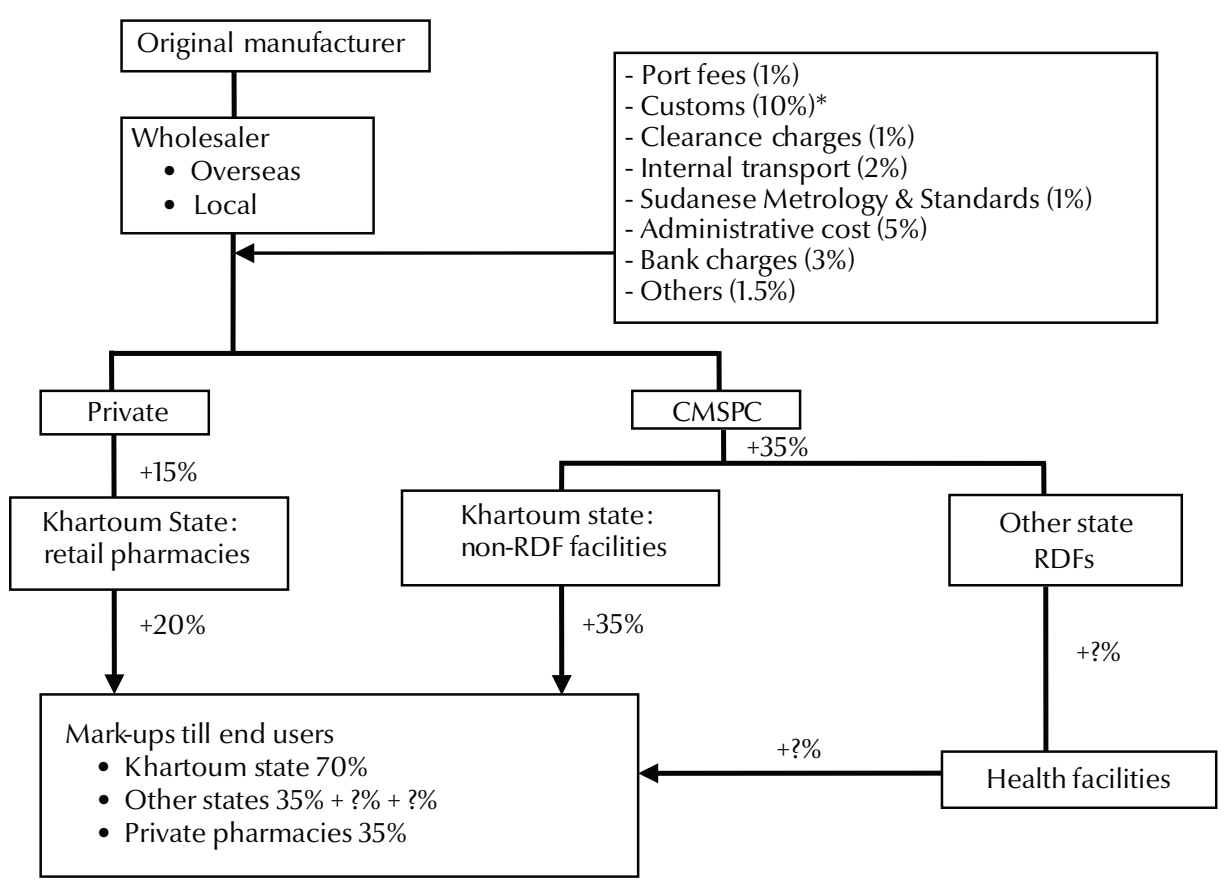

?\% Mark-up varies by state and its health facilities

$\mathrm{CMSPC}=$ Central Medical Supplies Public Corporation; RDFs = revolving drug funds

Sudan this is known as C\&F price) after consideration of various factors. The suggested price is agreed upon between the committee and an importer of medicines (the local agent for the manufacturer from abroad) before final registration of the medicine. The $\mathrm{C} \& \mathrm{~F}$ price of an innovator brand product is also determined by the same committee.

As shown in Figure 1, the original price of medicines is almost doubled before reaching the end users. According to the recently approved regulations by NMPB [9], the wholesalers should charge all pharmacy outlets equal medicine prices throughout the country regardless of the distance from their warehouses.

\section{Pricing system in the public sector}

In the public sector, procurement is carried out by the Central Medical Supplies Public Corporation (CMSPC). The $\mathrm{C} \& \mathrm{~F}$ price is determined by the tender committee. As shown in Table
1, costing is also done by CMSPC by adding a total of $24.2 \%$ and $29.0 \%$ to products that are shipped by air and sea respectively. Products of CMSPC are sold to public and private health facilities at a 20\% mark-up and at $12 \%$ mark-up for Revolving Medicine Funds (RDFs) at state levels. CMSPC sells medicines either directly to the federal hospitals or to the RDFs in other states which in turn sell them to the public health facilities (Figure 1). Each level adds its own mark-up before the medicines are finally sold to end users. Thus, any issues of cost recovery are problems for the institutions not CMSPC, and the original price of medicines is increased 2 or 3 fold before reaching the end users.

\section{Methods}

A price survey was conducted in Khartoum State between July and September 2008 to assess the adherence of importers/wholesalers of medicines and retail pharmacies to price of medicines set by NMPB. Data on the prices of the 50 most popular originator/innovator brands (the patented versions of the chemical entity first launched on the international market) and generics sold in the country in 2007 (regardless of their dosage-form and strength) were collected as well as on the medicines recommended by the WHO/HAI methodology to be included in such a price survey. We ended up with 174 medicines. A total of 39 were excluded from the analysis because they had missing information on their prices. Of the 135 medicines included, all were imported; 120 (89\%) were either generic or branded generics, and 15 products (11\%) were innovator brand medicines. Unit medicine prices were calculated by dividing the medicine pack $\mathrm{C} \& \mathrm{~F}$ selling price by the number of tablets, capsules, vials or doses contained.

Documentary evidence, mainly certificates of registration to collate C\&F prices and invoices to the pharmacies to gather data on whole and retail prices 


\begin{tabular}{|c|c|c|}
\hline \multirow[t]{2}{*}{ Price component } & \multicolumn{2}{|c|}{$\mathrm{C \& F}$} \\
\hline & $\%$ (By air) & \% (By sea) \\
\hline \multicolumn{3}{|l|}{ Fees (taxes) } \\
\hline Customs tax & 10.0 & 10.0 \\
\hline Wound tax ${ }^{\mathrm{a}}$ & 1.0 & 1.0 \\
\hline Port fees & 1.2 & 2.5 \\
\hline Total & 12.2 & 13.5 \\
\hline \multicolumn{3}{|l|}{ Other expenses } \\
\hline Clearance expenses & 7.0 & 7.0 \\
\hline Insurance & 2.0 & 2.0 \\
\hline $\begin{array}{l}\text { Other costs (e.g. retained, damaged products, unexpected, or unseen } \\
\text { expenses) }\end{array}$ & 1.0 & 1.0 \\
\hline Bank charges & 2.0 & 2.0 \\
\hline Transportation & - & 3.5 \\
\hline Total & 12.0 & 15.5 \\
\hline
\end{tabular}

${ }^{a}$ Removed in 2009.

$C \& F=$ cost and freight

that had been issued by NMPB and wholesalers respectively, was used to cross-check the adherence of medicine dealers to the prices (i.e. C\&F, wholesale and retail prices) approved by NMPB. Data on wholesale and retail prices, which are usually written on the invoice issued to retail pharmacies by the wholesalers, were collected by the researchers from the records of pharmacies. It was not our aim to decide upon a specific sample size of pharmacies for this research, as we were not primarily interested in numbers but in the completion of data on prices of selected medicines to find out to what extent wholesalers comply with the approved prices from the regulatory authority. The required data on wholesale and retail prices of the selected medicines were obtained from the first 5 pharmacies visited and hence there was not need to go to any others. Later, variations in prices were explored by interviewing key informants, i.e. pharmaceutical importers, policy-makers. The actual price (AP) displayed on the studied products by pharmacy was also reviewed to determine to what extent retail pharmacies are following the importers' declared retail price. It also gives an idea about the efficiency of the inspection activities conducted by state regulatory authorities. Finally, AP can help assess the effectiveness of the current practice of the medicine importers of printing the retail prices of their products on their invoices to present this to the end users.

Other relevant regulatory documents, such as pricing guidelines, were obtained and analysed. All policies and legislations, namely National Medicines Policy, laws, regulations, ordinances, decrees, and circulars, regarding medicine prices were included. Documents were collected throughout the duration of the study. The main sources of those documents were the NMPB, CMS, and community pharmacies. Interviews with key informants were conducted in order to further understand the pricing mechanism and the reasons behind the higher prices reported by WHO [4].

Components and determinants of prices were explored by interviewing key representatives of pharmacists, medicine importers and regulators on aspects of government charges, and history and impact of medicine prices in Sudan, as well as by collecting data on import prices and regulations. Interviews using open-ended questions were held in March 2009 after analysing survey data, so that the interviews could take account of the results. The interviews were conducted by the first author in the capital city, Khartoum. The interview sample was purposive and represented 3 groups: pharmacies, importers and regulators. A total of 10 informants were interviewed. Data from the interviews and documentary evidence were used to compare official approved prices by the NMPB with those charged by the medicine importers and pharmacies.

\section{Data analysis}

To measure the extent of compliance or deviation from the approved prices, we set theoretical benchmark for the wholesale price (WP) and retail price (RP). These prices were calculated by topping up government's charges to the registered $C \& F$ price for each item in the study (Figure 1). Theoretically, we found that the WP and RP should be 1.5 and 1.8 times the $C \& F$ price respectively (i.e. $\mathrm{WP} \div \mathrm{C} \& \mathrm{~F}=1.5$ and $\mathrm{RP}$ or $\mathrm{AP}$ $\div \mathrm{C} \& \mathrm{~F}=1.8$ ). To compare the prices of selected medicines with the median price of their equivalents published in the IRP, medicine price ratios (MPR) were determined for each medicine by relating prices derived from the survey 
to IRP. MPR was calculated as follows: $\mathrm{MPR}=$ medicine price (whether $\mathrm{C} \& \mathrm{~F}$, whole or retail $) \div$ IRP. Data were analysed with Microsoft Excel 2007.

Interviews were audio-recorded and transcribed in Arabic; relevant quotes and passages were then translated into English.

WHO set an arbitrary benchmark for the analysis of medicine prices in the countries of East Mediterranean Region (EMR) [4]. For the purposes of this study, we used the same benchmark to measure the efficiency of the current pricing mechanism by comparing the prices of selected medicines with those published in the IRP. In the case of publicly procured generic medicines, prices were considered "acceptable" if they had an MPR of 1 or less, which means that the price of the generic medicine was the same or less than the IRP for the same medicine. The MPR of the medicine in retail pharmacies was considered "acceptable", if it was less than 2.5. Prices above this, especially those of generic medicines, were considered "excessive".

\section{Results}

\section{Wholesale prices}

Only 15 out of 104 importing companies approved their wholesale and retail prices with the NMPB. According to the Act [3], wholesalers and retailers are not permitted to sell medicines at prices higher than those approved. However, at the time of the study, there were no regulations adopted by the NMPB to ensure the compliance of wholesalers and retailers with the approved medicine prices. One of the interviewees heavily criticized the medicine regulatory authority effort for controlling the pharmaceutical market in Sudan. He alleged that regulators in the 1990 s had a vested interest in guaranteeing a generous mark-up to the pharmacists.

"There is no control over medicine prices, for example, prices of certain generics are higher than their originators. The market has been overwhelmed by low quality medicines from countries, such as India and Pakistan."

This, together with the shortage of trained personnel and resources for assessing the reasonableness of submitted C\&F prices of medicines, has meant that most of the information on medicine prices declared by pharmaceutical companies has not been scrutinized. Not unexpectedly, this situation has been exploited by some unscrupulous medicine importers. For example, the C\&F price of $23 \%$ of the selected medicines was more than 10 times the IRP. Surprisingly, $71 \%$ of these items were generics. However, this might be due to the scale of production of such items that lead to high cost structures and hence the imposition of high prices. Using 1.5 times the $\mathrm{C} \& \mathrm{~F}$ as benchmark, the wholesale price of only $40 \%$ of studied medicines was less than 1.5. The majority ( $88 \%$ ) of these items were generics (full data not shown; available on request).

\section{Retail prices}

We verified the retail prices written on the invoices issued by the wholesalers of the studied medicines to retail pharmacies. According to the current price mechanism, the retail price should be 1.8 times the $\mathrm{C} \& \mathrm{~F}$ registered price. In fact the retail prices of up to $47 \%$ of the selected medicines were lower than this. The majority ( $87 \%$ ) of these items were generics (full data not shown; available on request). The retail prices of $11 \%$ of the items were less than their registered C\&F. According to the interviewees, this finding could be explained by the fact that these items were registered in the early 1990s, with very high C\&F prices. Theses medicines are mainly from Jordan and were imported by the government at very high prices during the period of economic sanctions. At that time, hard currency was not available and the government exchanged its sesame crop for medicines from Jordan.

\begin{tabular}{|c|c|c|c|c|c|c|}
\hline \multirow[t]{2}{*}{ Originator name } & \multicolumn{3}{|c|}{ C\&F price (CHF) } & \multicolumn{3}{|c|}{ Retail price (SDG) } \\
\hline & Originator & Generic $^{a}$ & Generic:Originator & Originator & Generic & Generic:Originator \\
\hline $\begin{array}{l}\text { Neurobion } 100 \text { mg, } 200 \text { mg, } \\
\& 200 \mu \text { g tablets - Austria }\end{array}$ & 3.17 & 5.25 & 1.7 & 12.80 & 44.00 & 3.4 \\
\hline $\begin{array}{l}\text { Neurobion injection - } \\
\text { Austria }\end{array}$ & 2.69 & 6.30 & 2.3 & 15.06 & 33.36 & 2.2 \\
\hline $\begin{array}{l}\text { Rocephin injection } 1 \mathrm{~g}- \\
\text { Germany }\end{array}$ & 11.00 & 18.50 & 1.7 & 45.50 & 78.46 & 1.7 \\
\hline $\begin{array}{l}\text { Voltaren } 100 \text { mg tablet - } \\
\text { Switzerland }\end{array}$ & 6.25 & 5.00 & 0.8 & 27.28 & 34.11 & 1.3 \\
\hline $\begin{array}{l}\text { Voltaren } 25 \text { mg tablet - } \\
\text { Switzerland }\end{array}$ & 5.55 & 3.90 & 0.7 & 24.22 & 26.61 & 1.1 \\
\hline Voltaren gel - Switzerland & 2.70 & 2.60 & 1.0 & 20.00 & 14.31 & 0.7 \\
\hline
\end{tabular}

${ }^{a}$ All generics originated from Switzerland.

$C \& F=$ cost and freight; $C H F=$ Swiss francs; $S D G=$ Sudanese pounds. 


\begin{tabular}{|c|c|c|c|c|c|c|c|c|}
\hline Trade name & Generic & $\begin{array}{c}\text { Strength } \\
(\mathrm{mg})\end{array}$ & $\begin{array}{c}\text { Dosage } \\
\text { form }\end{array}$ & BNF (SDG) & $\begin{array}{c}\mathrm{C} \& \mathrm{~F} \\
(\mathrm{SDG})\end{array}$ & $\begin{array}{l}\text { Retail } \\
\text { (SDG) }\end{array}$ & C\&F:BNF & Retail:BNF \\
\hline Tenormin & Atenolol & 50 & Tablet & 0.58 & 0.28 & 1.07 & 0.48 & 2 \\
\hline Glucophage & Metformin & 500 & Tablet & 0.37 & 0.23 & 0.48 & 0.64 & 1 \\
\hline Zantac & Ranitidine & 150 & Tablet & 1.38 & 0.78 & 1.35 & 0.56 & 1 \\
\hline Augmentin & Amoxicillin/clavulanic acid & 375 & Tablet & 0.68 & 1.06 & 2.04 & 1.56 & 3 \\
\hline Fefol & Ferrus + folic & $47+5$ & Capsule & 0.18 & 0.11 & 0.29 & 0.63 & 2 \\
\hline Tegretol & Carbamazepine & 200 & Tablet & 0.32 & 0.38 & 0.66 & 1.20 & 2 \\
\hline Buscopan & Hyoscine & 10 & Tablet & 1.48 & 0.19 & 0.34 & 0.13 & 0.2 \\
\hline Sporanox & Itraconazole & 100 & Capsule & 3.12 & 1.43 & 6.99 & 0.46 & 2 \\
\hline Motilium & Domperidone & 10 & Tablet & 0.24 & 0.29 & 0.5 & 1.21 & 2 \\
\hline Primolut-N & Norethisterone & 5 & Tablet & 0.21 & 0.48 & 0.78 & 2.26 & 4 \\
\hline Panadol & Paracetamol & 500 & Tablet & 0.06 & 0.10 & 0.18 & 1.65 & 3 \\
\hline Neo-Mercazole & Carbimazole & 5 & Tablet & 0.16 & 0.10 & 0.3 & 0.58 & 2 \\
\hline
\end{tabular}

$S D G=$ Sudanese pounds.

Later, similar generics were registered from other sources, such as India, China and Pakistan, at cheap C\&F prices. The importers of medicines registered during the sanctions period were forced by market competition to reduce their wholesale and retail prices without notifying the NMPB to change their old C\&F prices. Key informants interviewed argued that the NMPB's measures to control medicine prices were insufficient and they did not keep pace with the increased number of medicines registered in the highly competitive environment of the past decade.

The retail price of $7 \%$ of the items was 3 or more times more than the registered or approved $\mathrm{C} \& \mathrm{~F}$ price, i.e. a $300 \%$ mark-up on the C\&F price; again, $56 \%$ of these items were generics. At the same time, the retail prices of some innovator medicines were cheaper than their generics. For example, C\&F and retail prices for the generic neurobion ranged from 1.7 to 3.4 times higher than the originator Neurorubine forte ${ }^{\circ}(\mathrm{Ta}-$ ble 2). According to the interviewees, this was due to the registration of the generic before the innovator; a weak pricing system; intermittent availability of the innovator in Sudan; and the heavy promotion of the generic product by giving free goods. The interviewees said that patients had no choice and that their doctors and pharmacists, influenced by medical representatives, decided on their behalf.

The retail prices of 11 out of 12 originator brands were equal to or higher than their prices published in the BNF. Of these, 9 items were 2 or more times their BNF price. The highest price of an innovator medicine was Primolut- $\mathrm{N}^{\circ}$, whose price was 4 times higher than the BNF (Table 3). The C\&F (and not retail) price of a generic ranitidine tablet imported from Egypt was 500\% that published in the BNF.

\section{Actual consumers' price}

We also analysed the retail prices written on the invoices issued by the wholesalers to retail pharmacies with those displayed in the pharmacies and found low compliance with medicine pricing regulations; $9 \%$ of the 135 studied medicines were sold at prices less than their $C \& F$ prices. The retail price of 62 items ( $46 \%$ ) was either double (43 items) or more than double (19 items) their C\&F price. According to the interviewees, this was due to the lack of printed retail prices on the medicine pack. It also led to the differences in the price of the same brand in different pharmacies.
Pharmacies did not stick to the prices set by importers but rather the pharmacists adjusted final prices according to market demand. For example, the actual retail price to the consumers of about $75 \%$ of the selected items was more than the retail price declared by the wholesalers.

\section{Medicine prices in Sudan compared to international reference prices}

With the exception of only 5 generics, in all selected originator brands and generics the $C \& F$ and retail prices were consistently excessive in relation to the benchmark 2.5 used by WHO [4]. The $C \& F$ price of more than one-fifth of the studied items was more than 10 times the IRP; 17 out of 24 of these items were generics. The $C \& F$ prices of certain medicines were extraordinary high, up to 100 times the IRP. We also compared the retail prices written on the wholesalers' invoices issued to the pharmacies. Using the cut-off of MPR $\leq 2.5$, the retail prices determined by the wholesalers of around $60 \%$ of the selected items were between 5 and 10 times higher than the IRP. Again, 31 out of 40 of these items were generics. Three interviewees reported "... we noticed that the pricing of medicines before the 


\begin{tabular}{|c|c|c|c|}
\hline Country & Value (US\$) & $\%$ & Cumulative \% \\
\hline Jordan & 7210560 & 41.000 & 41.000 \\
\hline India & 3050245 & 17.344 & 58.344 \\
\hline Syrian Arab Republic & 2309182 & 13.130 & 71.474 \\
\hline Pakistan & 1187387 & 6.752 & 78.226 \\
\hline China & 1001704 & 5.696 & 83.921 \\
\hline Egypt & 710377 & 4.039 & 87.961 \\
\hline Saudi Arabia & 688284 & 3.914 & 91.874 \\
\hline Cyprus & 326205 & 1.855 & 93.729 \\
\hline Switzerland & 198765 & 1.130 & 94.859 \\
\hline United Kingdom & 176132 & 1.002 & 95.861 \\
\hline France & 172193 & 0.979 & 96.840 \\
\hline United Arab Emirates & 161236 & 0.917 & 97.757 \\
\hline Netherlands & 85026 & 0.483 & 98.240 \\
\hline Germany & 69174 & 0.393 & 98.634 \\
\hline Japan & 67750 & 0.385 & 99.019 \\
\hline United States of America & 49390 & 0.281 & 99.300 \\
\hline Turkey & 23313 & 0.133 & 99.432 \\
\hline Italy & 21277 & 0.121 & 99.553 \\
\hline Greece & 16302 & 0.093 & 99.646 \\
\hline Austria & 15652 & 0.089 & 99.735 \\
\hline Korea & 15217 & 0.087 & 99.821 \\
\hline Denmark & 14831 & 0.084 & 99.906 \\
\hline Slovenia & 7859 & 0.045 & 99.950 \\
\hline Spain & 7854 & 0.045 & 99.995 \\
\hline Malaysia & 855 & 0.005 & 100.000 \\
\hline Total & 17586770 & 100.000 & \\
\hline
\end{tabular}

establishment of NMPB was very subjective". The interviewees added that, "there were no criteria and it mainly relied on the documents and the argument made by the importers".

\section{CMS prices}

In order to make medicines more affordable and reduce the burden on households, the government - through the public sector - has focused on essential medicines, which are purchased through international competitive bidding. WHO reported that the CMS manages to buy generic medicines so efficiently through open tender, i.e. at a MPR of 0.2, the target set by WHO as benchmark is 1 or less [4]. In the public sector, although the tender prices recorded were largely below the did not benefit from tender by price reductions.

However, decision-makers at CMS attributed the high mark-ups on the tender prices to the high CMS operating expenses that resulted from maintaining certain stock levels of high cost, lifesaving items such as vaccines. In addition, they reported that this adjustment prohibits leakage of cheap medicines from public sector facilities to private ones and convinces people that CMS medicines are not low quality and at the same time keeps down the cost of obtaining medicines. As interviewees at CMS pointed out, some patients, including the poor, perceive cheap medicines as low quality.

\section{Promotion/propaganda allowance}

The value of free medicines imported to Sudan during the first 6 months of 2008 was US\$ 17.6 million (i.e. $30 \%$ of the value of medicines imported by the private sector) [National Medicines and Poisons Board, Annual report, 2008, unpublished]. The origins of these medicines were mainly Jordan, India and Pakistan (Table 4). Some importers gave from $50 \%$ to $100 \%$ free medicines per invoice. The interviewees who were against a free goods policy argued that this practice has weakened the control of medicine prices in Sudan. According to them, it is difficult for inspectors to trace the free medicines because it is left up to the pharmacies either to reduce their prices by spreading the cost of goods over all invoiced items or to sell the free goods as if they had paid for them. Interviews with importers who opposed the promotion argued that the bonus also distorts medicine prices and unnecessarily escalates their cost. Retail pharmacies tend to sell medicines of companies that offer free goods at the expenses of those who do not. Certain importers do not give free goods and rely mainly on promotion done by their medical representatives. Promotion is very 
effective tool and doctors prescribe the promoted products, but at the dispensing level, pharmacy staff substitute the products on the prescription with those from pharmaceutical companies that give free goods. This practice hits hard on patients who do not know the price of alternative medicines, which in most cases is cheaper. It is clear that the $C \& F$ prices of these medicines have been inflated by the importers and their principal manufacturers. This was confirmed by interviews with pharmacists working in medicine importing companies who explained that the cost of free goods is already added to the C\&F prices.

However, interviewees from medicine importing companies argued that any change in the current pricing system to impose more stringent control on C\&F prices and set low profit margins for importers favours current market operators and creates an informal barrier to entry of new comers from countries producing generics. Those interviewees thought that the current pricing system gave more leverage to the manufacturers and made Sudan an attractive market. Free goods helped importers to promote their new medicines and reduce their overheads by eliminating the budget line for promotion.

\section{Discussion}

Price regulation of medicines is especially important in settings where medicine shortages are common in public health facilities. This situation forces patients to purchase their medicines from the private sector [10], such as retail pharmacies, which are considered the most accessible source of medicines. Our findings confirm what has been reported by WHO [4] that the price of medicines in Sudan are comparatively higher than in countries of the Middle East. The fact that the prices of generic medicines do not follow economic theory [11] suggests that there must be some interference with the free market for generic medicines that is causing Sudanese prices to be higher than comparable countries in the region.

Using the current mechanism, medicine prices in Sudan cannot be easily controlled and the status quo remains. For example, in Egypt a medicine retail price is considered high, if it is more than $30 \%$ of the BNF price [A. Salih, unpublished report, 2007]. Our findings reveal that the $\mathrm{C} \& \mathrm{~F}$ price, and not the retail price, of a generic ranitidine tablet imported from Egypt was 500\% that published in the BNF. In the United Kingdom (UK), almost all the population is covered by the National Health Service, whereas in Sudan more than $70 \%$ of patients pay for medicines out of their own pocket [2]. According to $\mathrm{WHO}$, per capita expenditure on medicines in the UK is equal to US\$253 compared to only US\$ 4 in Sudan [12]. In addition, per capita gross domestic product (GDP) per year and per capita GDP at purchasing power parity (PPP) per year are totally different between the UK, Egypt and Sudan. The GDP per capita in PPP in the UK is 17 times that of Sudan and 6 times that of Egypt. In addition, public health expenditure in the UK is 106 times higher than Sudan, and 19 times higher than Egypt, and PPP in the UK is 19 times higher than in Sudan, 7 times higher than in Egypt [13]. These figures highlight the weakness of the current pharmaceutical price mechanism in Sudan, which appears to be disregarded by politically influential business men. There is evidence that some importers collude with foreign manufacturers to misreport $C \& F$ prices [14] and some retailers do not apply formal margins written on the invoices issued by importers. It seems that the weak medicine control departments at central and state levels and untrained inspectors enable importers and retailers to bypass the existing price regulations and make higher profits.
Cost can be a major barrier to adequate treatment, particularly in low-income countries [8]. Although a pharmacoeconomic evaluation is normally conducted to help inform budget allocation decisions, it could be of value in settings where patients pay for their medicines. A government regulatory authority needs to do such evaluation on behalf of the patients. As has been reported in many countries, such as Australia and Canada [15], pharmacoeconomic evaluations need to be a mandatory part of the dossier for the registration of new medicines and pricing in Sudan. Such a value-based mechanism for pricing of medicines will ensure patients access to clinically effective and cost-effective medicines.

Without stringent national medicine pricing regulations that can help to lower the medicine price in both the private and public sectors, consumers will find it difficult to access even life-saving medicines. Our study also found that some generics cost more than innovator medicines. This could be attributed to the lack of medicine price regulations and weak medicine pricing system adopted by NMPB in Sudan, where the majority of importers fix the whole and retail prices of their medicines without NMPB approval. The study findings therefore highlight the need for national medicine pricing regulations in order to control the level of mark-up that wholesalers and retail pharmacies can apply to medicines, which in turn will increase the accessibility of medicines to the population. The level of mark-up should aim not only to increase accessibility of medicines but also the viability of the business of both wholesalers and retailers of pharmaceuticals in Sudan. The inspection and supervision systems at both federal and state levels need to be more frequent and effective. Training of inspectors and necessary logistics should be in place. Finally, the NMPB needs to review medicines prices regularly. The price revision ensures 
affordable prices for patients and enables the medicine importers to maintain their ability to make profit.

There is a lack of transparency in the current pricing mechanism. As a result, new legislation and associated regulations must ensure transparency of medicine prices along the supply chain. The new regulations need to address all the preconditions necessary for the laws to operate effectively in practice. These include clear criteria for calculating the C\&F price, agreement on the different government charges to be included in the cost, a decision on the mark-up for wholesalers and retailers, and a specified penalty for selling at higher prices the registered, published prices. To be successful, the regulations must be enforced and their impact on accessibility of medicines must be monitored.

The current fixed mark-ups, i.e. 15\% and 20\%, encourage both wholesalers and retailers to sell products of high C\&F prices. The new pharmaceutical regulations must legally obligate the importers to fix sliding mark-ups for whole and retail prices ranging from, for example, $15 \%$ to $20 \%$ and $20 \%$ to $25 \%$ respectively, depending on the total cost to their warehouses in Khartoum. This also needs to be publicly regulated and enforced by NMPB. This could be done through the publication of medicine retail price on the outer package. The sliding scale of putting highest mark-up on lowest C\&F prices will encourage wholesalers and retailers to buy low cost medicines rather than the more expensive products.

From the findings of this survey it is most likely that the costs of the medicines freely distributed to the pharmacies are added to the total costs and hence contribute to higher C\&F prices. A policy on free goods is needed to rectify the situation. Such a policy should, however, reduce the retail prices while limiting or prohibiting the bonus. Although this would reduce the profit of the pharmacies, it would reduce the burden on the patients and on the health system as a whole. The question why Jordan offers large quantities of free goods needs to be answered.

There are several limitations to this study that need to be acknowledged and the findings need to be interpreted with caution. First, the actual retail prices are not generalizable to the whole country since we only selected 5 pharmacies from urban areas in Khartoum State. However, there is some justification for this since all the wholesalers are in Khartoum. In addition, in Sudan, each wholesaler imports its own medicines and sells them directly to the retail pharmacies, i.e. there are no brokers between wholesalers and retailers; and all importers print whole and retail prices on their invoices of medicines issued to retail pharmacies, regardless of where the pharmacies are. Second, the survey used a different sampling method from the WHO and Health Action International (HAI) methodology, which indicates whether prices are high or low in developing countries. Thus the approach has not been validated by large-scale studies and the results may not be reliably comparable to those obtained using the WHO/HAI methodology elsewhere. The purpose of our study was different from that of WHO/ HAI and our findings could be used as evidence that the current pricing system does not work.

\section{Conclusion}

Little compliance with official price regulations was observed at all stages of the pharmaceutical distribution chain. Lower prices at CMS does not help much in controlling of prices in the private sector, because retail pharmacies sell the low-cost tender items from CMS at the high retail prices set by their wholesalers. Private-sector retail pharmacies benefit from this practice and make large profits using this privilege. The current pricing system, in both public and private sectors, is of limited benefit in controlling escalating medicine prices in Sudan. A new price mechanism should be put in place to avoid stretching what is in many cases inadequate household income. The NMPB needs to step up its supervision and monitoring efforts regarding medicine prices. Our study contributes in a number of ways to the existing debate on medicine prices in low-income countries. It shows the importance of fixing cost and profit mark-ups for both private and public sectors for each stage of medicines distribution in order to improve access to medicines. National mark-ups can be at least as important as C\&F prices for the determination of medicine prices. The research also shows that the belief that the prices of generic medicines that have been imported from cheap sources, such as India and China, as well as those have been purchased through public open tenders is lower may be oversimplified and not in fact the case.

\section{Acknowledgements}

This study was funded by the National Medicines and Poisons Board.

We acknowledge the work done and contributions made by many officers who have worked with NMPB from its inception. We also acknowledge the continued commitment of his Excellence the Vice-President and the Ministry of Health to the NMPB during the establishment period and to date. Finally, the achievements of the NMPB could not have been possible without commitment from the chambers of medicine importers and manufacturers. We also appreciate support of Abobakr Abdelraof, Mohamed Abdelrahman, Yasir Abuelrish and Abdelhamid Ibrahim for their help and advice. 


\section{References}

1. Sudan in Figures: 2005-2009. Khartoum, Sudan, Central Bureau of Statistics, 2012

2. Global health expenditure database. Geneva, World Health Organization, 2010. (http://apps.who.int/nha/database/StandardReport.aspx?ID=REPORT_2_WHS, accessed 30 May 2012).

3. Pharmacy, Cosmetics and Poisons Act. Khartoum, Sudan Federal Ministry of Health, 2001.

4. Technical discussion on medicine prices and access to medicines in the Eastern Mediterranean Region. Cairo, World Health Organization, Regional Office for the East Mediterranean, 2007. (EM/ RC54/Tech.Disc.1). (http://www.scribd.com/doc/78173351/ WHO-2007, accessed 25 June 2012).

5. Aaserud $\mathrm{M}$ et al. Pharmaceutical policies: effects of reference pricing, other pricing, and purchasing policies. Cochrane Database of Systematic Reviews, 2006, 2:CD005979.

6. International Drug Price Indicator. Cambridge, MA, Management Science for Health \& on behalf of the World Health Organization, 2008. (http://erc.msh.org/dmpguide/pdf/ DrugPriceGuide_2008_en.pdf, accessed 30 May 2012).

7. British National Formulary, 56th ed. London, BMJ Group and Pharmaceutical Press, 2008.

8. Management Science for Health \& World Health Organization. Managing drug supply: the selection, procurement, distribution and use of pharmaceuticals, 2nd ed. West Hardford, CT, Kumarian Press, 1997.
9. Regulations for the registration of pharmaceutical products 2008. (http://www.nmpb.gov.sd./Regulations/Pharmaceutical\%20Products\%20Regulations\%202009.pdf, accessed 30 May 2012) [In Arabic].

10. Mohamed GK. The impact of the RDF on accessibility of medicines: experience of Khartoum State - Sudan. Saarbrücken, Germany, Lambert Academic Publishing, 2010.

11. Babar Z et al. Evaluating drug prices, availability, affordability, and price components: implications for access to drugs in Malaysia. PLoS Medicine, 2007, 4(3):e82 (http://www. plosmedicine.org/article/info\%3Adoi\%2F10.1371\%2Fjournal. pmed.0040082, accessed 30 May 2012).

12. The World Medicines Situation. Geneva, World Health Organization, 2004 (WHO/EDM/PAR/2004.5).

13. Human development report 2009. Overcoming barriers: human mobility and development. New York, United Nations Development Fund, 2009 (http://hdr.undp.org/en/media/ HDR_2009_EN_Complete.pdf, accessed 30 May 2012).

14. Federal Pharmacy and Poisons Board. A proposal to reduce medicines price in Sudan. Paper presented at the Medicines Price Workshop held by the Federal Ministry of Health in collaboration with the World Health Organization Sudan Office, 12 November 2008, Khartoum, Sudan.

15. Walley T, Haycox A. Pharmacoeconomics: basic concepts and terminology. British Journal of Clinical Pharmacology, 1997, 43:343-348.

\section{WHO/Health Action International Project on Medicine Prices and Availability}

The Project on Medicine Prices and Availability is a collaborative partnership between WHO and the international non-governmental organization Health Action International. It is an outcome of the Public Interest NGOs WHO Roundtable on Pharmaceuticals, established in 1998 to strengthen collaboration between WHO and civil society. The Project is also supported by a resolution of WHO Member States at the 54th World Health Assembly in 2001 calling for the development of "systems for voluntary monitoring drug prices and reporting global drug prices" (Resolution WHA 54.11).

A key achievement of the project has been the development of an innovative standardized survey methodology for measuring medicine prices, availability, affordability and price components. The survey manual was launched at the World Health Assembly in 2003 as a working draft for field testing. Following the application of the methodology in numerous countries, a revised edition of the manual was published in 2008.

Further information about the Project is available at: http://www.who.int/medicines/areas/access/Medicine_Prices_ and_Availability/en/index.html 